\title{
Uma Proposta de Ensino de Inglês nas Salas de Aula do IFSC em Tempos de Globalização e Bilinguismo
}

\author{
A proposal for English teaching in the classrooms of IFSC in times of \\ globalization and bilingualism
}

José Carlos Martins*

*Instituto Federal de Santa Catarina, IFSC, Florianópolis - SC, 88020-300, e-mail: jose.martins@ifsc.edu.br

RESUMO: O presente trabalho traz uma reflexão, a partir da perspectiva da Linguística Aplicada Crítica, para o ensino de língua inglesa nas salas de aula dos cursos do Instituto Federal de Educação, Ciência de Tecnologia de Santa Catarina - IFSC (mais precisamente para os cursos de ensino médio integrado ao ensino técnico), reflexão também cabível a outras instituições e escolas. No artigo, discute-se criticamente o papel do IFSC quanto ao ensino de inglês ante o processo de globalização/globalismo com suas demandas por bilinguismo. Procura-se refletir que ensino de inglês se quer no IFSC, respondendo-se à pergunta: Que abordagem de ensino de inglês caberia ao IFSC no atual contexto? A percepção do artigo é de que na atualidade o ensino de inglês não pode mais se ater ao ensino da língua pela língua, mas que aconteça por meio de uma concepção libertária, que, além de preparar os aprendizes para o mundo do trabalho, dê-lhes a possibilidade de crescerem como cidadãos críticos engajados na organização de um mundo mais humano, mais justo.

PALAVRAS-CHAVE: globalização; bilinguismo; ensino de inglês.

ABSTRACT: This article discusses, departing from Critical Applied Linguistics perspectives, English language teaching in the classrooms of the Instituto Federal de Educação, Ciência e Tecnologia de Santa Catarina - IFSC (Federal Institute of Education, Science and Technology of Santa Catarina) - more specifically about high school courses integrated to technical teaching, a discussion also useful to other institutions and schools. In the article, the role of IFSC is critically discussed regarding English teaching in the present globalization/globalism era with its demands for bilingualism. A reflection about what kind of English teaching is desirable for IFSC is presented, trying to answer the following question: Which approach of English teaching could be applied to IFSC in the current context? The understanding in the article is that nowadays teaching of English should not be performed any more as a mere study of a language, but that that teaching may occur through a libertarian conception, which, besides preparing the students to the world of work, gives them the possibility to grow as critical citizens, engaged in the organization for a more humane and just world.

KEYWORDS: globalization; bilingualism; English teaching. 
INTRODUÇÃO

O mundo em que se insere a linguagem e seus usuários (falantes, aprendizes, escritores, intérpretes e outros) na atualidade é caracterizado pela interconectividade, a qual se destaca, principalmente, por meio da comunicação eletrônica, pela internet, pela diminuição de fronteiras, pelas transações comerciais entre povos, pelo domínio hegemônico de nações, processos a que se tem dado o nome de globalização (KUMARAVADIVELU, 2006). Busca-se neste artigo discutir a relação entre globalização, bilinguismo e o papel do ensino de inglês no contexto globalizado, levando-se em conta o Instituto Federal de Educação, Ciência e Tecnologia de Santa Catarina (o IFSC) e suas especificidades, e de que maneira esse ensino pode ser tratado na atualidade; isso a partir das perspectivas da Linguística Aplicada Crítica, doravante LAC.

A LAC vê e analisa a linguagem de forma não-dissociada de seu contexto, dentro ou fora das fronteiras escolares; vê e analisa a linguagem como fruto das relações estabelecidas por seus usuários; busca entender e revelar motivações sociais, culturais, políticas, ideológicas, de dominações envolvidas na multiforme manifestação da linguagem.

A LAC, nas suas análises e discussões, vale-se de teorias e concepções diversas, manifestando um caráter realizante interdisciplinar, transdisciplinar e multidisciplinar (CAVALCANTI, 1986; CAVALCANTI; MOITA LOPES, 1991; MOITA LOPES, 2013; KUMARAVADIVELU, 2006; PENNYCOOK, 2001; RAJAGOPALAN, 2005). Para Pennycook (2007, p. 68), a Linguística Aplicada Crítica "possibilita todo um novo conjunto de questões e interesses, tópicos tais como identidade, sexualidade, acesso, ética, desigualdade, desejo ou reprodução de alteridade [...]” são de interesse da área.

Cabe frisar que a discussão levantada neste artigo é pertinente não somente ao IFSC, mas também serve de reflexão a outras escolas e instituições, onde o inglês é ensinado em cursos profissionalizantes e não-profissionalizantes.

A discussão do ensino de inglês, que é desenvolvida neste artigo, leva em conta as concepções de globalização e globalismo a seguir esboçadas. No artigo, discute-se criticamente o papel do IFSC quanto ao ensino de inglês no processo de globalização. Por outro lado, também valoriza-se e destaca-se o trabalho do IFSC para o fortalecimento de um país que busca o seu espaço internacional em meio à hegemonia 
de países ricos. Procura-se entender que ensino de inglês se quer no IFSC, respondendose à pergunta: Que abordagem de ensino de inglês caberia ao IFSC na atualidade?

A estrutura de exposição deste artigo compõe-se de três partes. Em um primeiro momento, noções e entendimentos do que seja globalização e globalismo são apresentadas. Em segundo lugar, discute-se o significado de bilinguismo e sua importância para este trabalho. Em terceiro lugar, proposições de resposta para a pergunta acima são feitas. Na tentativa de se responder a essa pergunta, primeiramente, é apresentada a perspectiva de ensino de linguagem presente na missão do IFSC, e, em seguida, sugere-se e discute-se a concepção de ensino de inglês cabível ao IFSC a partir da sua missão. Essa discussão parte de uma segunda pergunta: A partir de que concepção essa perspectiva (de formação integral, de sujeito consciente, com visão crítica) constante na missão do IFSC pode ser contemplada no contexto atual? Por último, as considerações finais são apresentadas.

\section{GLOBALIZAÇÃO E GLOBALISMO}

A globalização não é algo novo, mas é um fenômeno sócio-político-econômico que ocorre desde o passado, fenômeno conhecido como processo trans-histórico de globalização, ou globalização arcaica, significando os impactos regionais e intercontinentais dos impérios agrários antigos, tais como: Qing (última dinastia imperial da China), Mughal (dinastia indiana), Togukawa (dinastia japonesa, no Japão e em Java), Otomano (dinastia turco-otomana, compreendendo a Anatólia, o Oriente Médio, parte do norte da África e do sudeste europeu), Romanov (dinastia russa) e Habsburgo (dinastia austríaca). (COLLINICOS, 2007).

Por outro lado, o fenômeno global moderno passou a se expandir a partir da $2^{\mathrm{a}}$ Guerra Mundial, e o globalismo se estabeleceu, mais precisamente, a partir do início da década de 1990, com o fortalecimento das propostas de livre mercado como estratégia à renovação do capitalismo, chamado de 'novo capitalismo' (ou neoliberalismo).

O globalismo, para Fairclough (2006, p. 7), é uma forma neoliberal de

liberalização e integração global de mercados, difusão de uma visão de democracia (ocidental), cujas estratégias visam a uma mudança para a direção de uma globalização neoliberal [...], é uma estratégia para raptar a globalização e colocá-la a serviço de interesses particulares nacionais e corporativos (FAIRCLOUGH, 2006, p.7, minha tradução). 
O mesmo autor apresenta a globalização a partir de quatro formas de se concebêla; as quais podem aparecer, muito comumente, inter-relacionadas nas sociedades. São elas: objetivista, retoricista, ideologista e socioconstrutivista.

Na visão objetivista, a globalização é um processo (grupo de processos), o qual encarna a transformação na organização espacial das relações e transações sociais (avaliadas quanto à extensão, intensidade, velocidade e impacto), gerando fluxos transcontinentais ou inter-regionais e redes de atividades, redes de interação e redes de exercício do poder.

$\mathrm{Na}$ concepção retoricista, a globalização se manifesta como discurso estratégico, persuasivamente usado para legitimar e autorizar práticas, especialmente, políticas e econômicas. Os discursos políticos e ações políticas, econômicas e sociais são validados por meio da afirmação de que o contexto de globalização demanda determinadas ações e intervenções, não cabendo críticas, mas aceitação das condições postas.

Na perspectiva ideologista (globalista), a globalização é usada como ideologia neoliberal, que serve como pretexto para a expansão dos padrões ocidentais, das chamadas democracias ocidentais - ou seja, é globalismo, como visto acima, nas palavras de Fairclough (2006). Também, é instrumento ideológico de prescrição e não de descrição, o qual atrela o processo global ao mercado livre (FAIRCLOUGH, 2006; STEGER, 2005), associado à ideia de hegemonia imperialista, muito traduzida pelas palavras ocidentalização, americanização ou McDonaldização (COUPLAND, 2010).

Por fim, na visão socioconstrutivista, a globalização não é apenas um fato, um discurso, uma ideologia, mas é percebida como fruto das relações sociais; a sua construção se dá também pelo consentimento e conveniência dos que a ela se submetem.

Para Appadurai (1990, p. 296-299, minha tradução), a globalização pode ser entendida como "uma ordem complexa coincidente e disjuntiva" manifestada por cinco categorias de forças e fluxos denominados por ele de paisagens, as quais são:

1- Etnopaisagem - fluxos de pessoas no mundo como "turistas, imigrantes, refugiados, exilados, trabalhadores e outros grupos em movimento".

2- Tecnicopaisagem - "configuração global sempre fluida, de alta e baixa tecnologia, tanto mecânica como informacional, movendo-se rapidamente através de vários tipos de fronteiras anteriormente impenetráveis". 
3- Financiopaisagem - diz respeito a fluxos monetários, bolsas de valores, especulações financeiras e de commodities, acontecendo em velocidade imperceptível.

4- Midiapaisagem - fluxos de informações por meio de jornais, revistas, satélites, televisão, Internet, criando narrativas diversas.

5- Ideopaisagem - "concatenações de imagens direcionadas politicamente e tendo a ver com ideologias de Estados e contraideologias de movimentos [...]”. Está ligada a termos como liberdade, bem-estar, direitos, soberania, representação, democracia.

A globalização, portanto, muito fortemente expressa por meio da face globalista nas relações internacionais, exerce acentuada demanda sobre os cidadãos, exigindo-lhes cada vez mais competências comunicativas, dentre as quais aparece o domínio de outras línguas, fazendo com que o bilinguismo seja algo a ser alcançado por muitos. Entendese que falar uma língua estrangeira é requisito indispensável ao cidadão contemporâneo. Essa demanda por novas línguas envolve jovens e adultos trabalhadores, que buscam suprir a sua "defasagem" bilíngue. O domínio de outra língua pode fazer a diferença na hora de uma entrevista de emprego, pois é uma exigência cada vez maior no mundo do trabalho.

A seguir, é apresentada, brevemente, a concepção de bilinguismo usada neste artigo bem como são citados benefícios advindos do domínio de mais de uma língua, independentemente de qual das quatro habilidades (fala, audição, leitura, escrita) se destaque mais no usuário da língua.

\section{BILINGUISMO}

A noção de bilinguismo, da qual se faz uso aqui, não é a que retrata um bilíngue “ideal”, com capacidade para comunicar-se perfeitamente em ambas as línguas, mudando de uma para a outra sem apresentar nuances da primeira ou da segunda, mas é uma noção de bilinguismo que, dependendo do contexto, diante de necessidades temporais e locais, o indivíduo poderá se sair melhor em uma delas, ou mesmo usar as duas ao mesmo tempo, pois "[o] bilíngue - não o idealizado, mas o de verdade - não exibe comportamentos idênticos na língua X e na língua Y” (MAHER, 2007, p. 73).

Dessa forma, o bilinguismo aqui destacado é aquele que, dadas as circunstâncias, faz uso de pelo menos uma das quatro habilidades, em outra língua, que não seja a de nascimento (GROJEAN, 2010; MEGALE, 2012), podendo apresentar variados níveis de proficiência. Portanto, um usuário de uma outra língua poderá 
procurar desenvolver muito mais a escrita do que a fala, ou vice-versa, se a sua necessidade for essa. O que foi dito é corroborado pela afirmação de Shin (2013, p. 4, minha tradução):

$\mathrm{Na}$ realidade, portanto, bilíngues raramente terão proficiência balanceada em suas duas línguas. Termos como bilíngues 'plenos' e bilíngues 'balanceados' representam concepções idealizadas que não caracterizam a grande maioria dos bilíngues do mundo. Raramente algum bilíngue será igualmente proficiente em falar, ouvir, ler e escrever ambas línguas em diferentes situações e domínios. Em outras palavras, um bilíngue não é a soma de dois monolíngues. Contudo, a visão monolíngue do bilinguismo está tão enraizada no pensamento popular e da escola ao ponto de até mesmo bilíngues se desculparem com monolíngues por não falarem a língua destes também como monolíngues, assim aceitando e reforçando o mito [de que bilíngues são como monolíngues].

O bilinguismo é tido como favorável aos que dele fazem uso pelo fato de, além de outros pontos importantes, implicar atividades cognitivas, desenvolver a comunicação, aguçar a capacidade criativa, como aponta Maher (2007, p. 71), ao dizer que

parece haver uma relação positiva entre bilingüismo, funcionamento cognitivo e competência comunicativa. Aumento do pensamento divergente/criativo, maior predisposição ao pensamento abstrato, maior consciência metalingüística, maior sensibilidade para o contexto de comunicação são apenas algumas das vantagens freqüentemente associadas ao bilingüismo na literatura especializada.

Partindo do princípio de que o bilinguismo no mundo globalizado é de reconhecido valor por favorecer o cidadão ao capacitá-lo para os desafios contemporâneos, permitindo-lhe “o acesso a uma ampla rede de comunicação e à grande quantidade de informações presentes na sociedade atual” (BRASIL, 2002, p. 67), é necessário que se problematize que bilinguismo, neste caso, o ensino de inglês, caberia ser praticado no IFSC no atual contexto. Isso é o que será discutido a seguir.

QUE ABORDAGEM DE ENSINO DE INGLÊS CABERIA AO IFSC NA ATUALIDADE?

Neste ponto, discute-se, mais precisamente, como o ensino de inglês pode ser abordado no Instituto Federal de Santa Catarina na atualidade marcada pela acentuação de diferenças positivas e negativas. As diferenças positivas podem ser compreendidas 
como situações em que as pessoas são valorizadas com suas marcas identitárias diversas, expressas nas manifestações culturais, políticas e sociais, e isso como direito. As negativas são percebidas como situações em que se procuram estancar, apagar essas manifestações e encerrar as pessoas debaixo de uma visão única de manifestação, marginalizando, discriminando e cerceando liberdades e direitos.

A discussão, primeiramente, lida com a perspectiva de ensino de linguagem presente na missão do IFSC (de formação integral, de sujeito consciente, com visão crítica), trazendo à tona a dicotomia de um ensino que coopera com a globalização estabelecida, mas que ao mesmo tempo procura cumprir o papel de promover a autonomia dos aprendizes. Posteriormente, a discussão procura problematizar a partir de qual concepção essa perspectiva constante na missão do IFSC pode ser contemplada no atual contexto.

Cabe frisar que neste ponto não se discute a opção por uma determinada teoria de aprendizagem e ensino ou outra. Não se trata de métodos específicos a serem adotados, qual o mais pertinente ou não, ou de abordagens específicas, já há tempo estabelecidas, como a estruturalista ou a comunicativa. Mas se discute uma perspectiva em que o estudo de outra língua pode acontecer sem dissociar o estudante da realidade de mundo em que vive, com as suas possíveis desigualdades, as quais precisam ser entendidas, criticadas e alteradas para dar lugar a espaços mais iguais e humanos.

O que de fato poderia ser dito, quanto a métodos e abordagens, é que a perspectiva de ensino de outra língua constante na missão do IFSC não teria como se coadunar com métodos e abordagens estruturalistas, os quais se preocupam muito especificamente com pontos gramaticais, vocabulário (isolado), exercícios estruturais (descontextualizados), tendo como características a ausência de pensamento reflexivo, de crítica, de questões contextuais sociais.

\section{PERSPECTIVA DE ENSINO DE LINGUAGEM NA MISSÃO DO IFSC}

O Plano de Desenvolvimento Institucional do IFSC (2014, p. 27), o PDI, estabelece a missão da instituição, qual seja "[p]romover a inclusão e formar cidadãos, por meio da educação profissional, científica e tecnológica, gerando, difundindo e aplicando conhecimento e inovação, contribuindo para o desenvolvimento socioeconômico e cultural", o que o PDI de 2009 explicava bastante claramente também: 
Nessa perspectiva, a educação, é um espaço fundamental para a formação integral do cidadão, sujeito consciente, com visão crítica e, sobretudo, atuante na sociedade. Mobilizar-se nessa direção significa condenar toda e qualquer ação que repercuta em exploração e submissão do Ser Humano e atuar para humanizar o globo e não globalizar o homem. Implica defender, nas práticas cotidianas, a solidariedade, a ética, a igualdade social, o reconhecimento das diferenças, a liberdade e o respeito à natureza. (PDI IFSC, 2009, p. 22, ênfase dos autores).

Nessa missão, insere-se o ensino de língua estrangeira, respondendo às Diretrizes Curriculares Nacionais para Educação Profissional Técnica de Nível Médio, que direcionam o ensino médio para o "desenvolvimento do mundo do trabalho, na perspectiva da formação integral do cidadão trabalhador" (BRASIL, 2013, p. 209).

É com essa perspectiva de formação integral do cidadão trabalhador que o IFSC oferece ensino de inglês nos seus diversos cursos e programas trazidos às comunidades onde atua. O inglês é oferecido (não necessariamente em todos os seus campi) em cursos técnicos integrados, em técnicos concomitantes, técnicos subsequentes, ProejaFic, Proeja Técnico, Mulheres Sim, cursos de Formação Inicial Continuada (FIC), em cursos superiores. Porém, a abordagem deste artigo leva em conta, mais especificamente, os cursos técnicos integrados, nos quais os estudantes fazem o ensino médio obrigatório, articulado integradamente com um curso técnico profissionalizante, conforme a LDB, Art. 36-C (BRASIL, 1996).

O IFSC, com sua missão e educação profissional, insere-se no contexto de globalização e globalismo e suas paisagens, dentro das perspectivas vistas em Appadurai (1990) e Fairclough (2006). Esse contexto marcado, principalmente, por uma economia de mercado de tendência liberal, a qual é caracterizada pela intensa concorrência, com exigência de excelência de serviços, demandas por fortes investimentos em tecnologia, requisição por serviços de primeira qualidade e profissionais preparados, situações em que os conceitos de qualificação e competência se evidenciam.

Esse contexto pode trazer dois cenários sociais: por um lado, as pessoas são chamadas a sair do comodismo do passado, a criar, a inovar, a se atualizar, a crescer, a pensar. Por outro lado, os efeitos colaterais são incertezas, pressão, demandas o tempo todo (cada vez mais se estuda, se qualifica, se prepara e não se tem garantia de sucesso). A volta aos estudos para muitos, buscando concluir a educação básica que havia ficado para trás, o ingresso num curso concomitante ou subsequente, numa nova graduação ou 
pós-graduação, pode ser entendida como resultado da pressão do contexto vivido (de globalização e globalismo), e sem ou com baixa escolaridade as chances de emprego se reduzem fortemente.

O IFSC, como fruto da expansão da Rede Federal de Educação Profissional, Científica e Tecnológica, na sua atuação, também, acaba por atender a interesses dessa globalização e globalismo excludentes ao preparar profissionais para o modelo de mercado que está posto, para um mundo mercantilizado, que garante poder aos países dominantes. Porém, também, o IFSC faz contraponto ao cenário posto quando coopera educacionalmente para fortalecer a nação, a qual busca ser competitiva e ter voz política e econômica para fazer frente às exigências do mercado internacional. O IFSC, semelhantemente, faz contraponto ao cenário posto quando desempenha a sua missão profissionalizante e corrobora para que o país e não deixe a sua população se tornar refém de nações que querem impor e manter a sua hegemonia econômica mundial, o que não se consegue mais com modelos tradicionais de força de trabalhadores, sem profissionais bem preparados atuando no país, que sejam capazes de interagir por meio de línguas estrangeiras.

Sendo assim, é necessário questionar que abordagem dar ao ensino de inglês, tendo em face a missão do IFSC de promover o desenvolvimento de cidadãos, através de conhecimento libertário (para vida), e ao mesmo tempo formar profissionais qualificados, atendendo às demandas do mundo de trabalho.

\section{A PARTIR DE QUE CONCEPÇÃO ESSA PERSPECTIVA (DE FORMAÇÃO INTEGRAL, DE SUJEITO CONSCIENTE, COM VISÃO CRÍTICA) CONSTANTE NA MISSÃO DO IFSC PODE SER CONTEMPLADA NO CONTEXTO ATUAL?}

Aqui, caberia a reflexão que o ensino de inglês pode ser uma forma de convergência aos interesses neoliberais, nos moldes pelos quais Fairclough (2006) vê a globalização, ou pode ser uma forma de construção/autoconstrução de cidadãos bilíngues críticos que se valham do inglês para questionar, propor mudanças, resistirem a imposições de interesses de poder.

Ainda, cabe a reflexão que o inglês ensinado no IFSC, ou em outras instituições e escolas, seja percebido, também, como sendo parte de uma força de poder global que deve ser questionada, a partir de uma visão crítica, transgressora (Freitas, 2013), pois, como diz Pennycook (2007, p. 22), “as sociedades são desigualmente estruturadas e são 
dominadas por culturas e ideologias hegemônicas que limitam as possibilidades de refletirmos sobre o mundo e, consequentemente, sobre as possibilidades de mudarmos esse mundo". A língua inglesa "não pode mais ser tomada como simplesmente ensino de língua" (HOLBOROW, 1996, p. 172).

O ensino da língua inglesa no IFSC pode assumir um caráter libertador se contribuir para que os estudantes sejam agentes de mudanças pessoais e sociais e tenham o entendimento de que o inglês, hoje, não pertence a uma, duas ou três nações poderosas, países anglófonos e seus habitantes nativos ou não-nativos, países aos quais se deve subserviência (segundo os interesses globalistas), mas que se tornou língua internacional, língua dos cidadãos do mundo, que não possui um único dono. Ela é língua, atualmente, caracterizada pelos vários ingleses, “world Englishes” (KACHRU; NELSON, 2005, p.9) - falados por várias populações do mundo, em diversas regiões onde o inglês não era a língua-mãe ou de herança -, fruto de uma mobilidade de populações que "nos tem feito conscientes do fato que determinadas línguas não pertencem a territórios ou Estados; antes pertencem às pessoas que as falam, que estão em diferentes espaços geográficos" (GARCIA, 2009, p. 26), absorvendo características locais.

Essas línguas inglesas vêm abrangendo as mais variadas áreas das inter-relações humanas (em que léxico, pronúncia e idiomatismos próprios dos locais vão sendo incorporados) e exercem importante papel no desenvolvimento dos cidadãos, dandolhes espaço e poder para se expressarem e interagirem em ambiente global. Muitas dessas línguas inglesas (essas variedades), apesar de terem sua inserção em sociedades a partir de conquistas colonizadoras, de dominação, tornaram-se veículo de vozes dissonantes a imposições internas e externas, vozes de transformações sociais. Observase isso na Nigéria, por exemplo, país que tem o inglês como idioma oficial, usado por instituições governamentais, onde diversas camadas da sociedade, além das línguas locais africanas, falam o inglês. São muitos os cidadãos nigerianos que vêm ganhando voz e força nas suas lutas e reivindicações, usando o inglês para fazer ouvir as suas reclamações nas mais variadas esferas de representação mundial (UDOFOT, 2010).

O uso da língua inglesa para fins específicos, devido ao caráter técnico do IFSC, não deve ser desprezado. É importante que se consiga usá-la como instrumento e habilidade que favoreça o futuro profissional, mas que o lado crítico, solidário, emancipatório seja marca da construção do cidadão como os PCNEM observam, 
quando tratam da economia de conhecimento (que usa o conhecimento para fins econômicos), a qual tem na sua base a tecnologia da informação e comunicação (TIC):

A expansão da economia pautada no conhecimento caracteriza-se também por fatos sociais que comprometem os processos de solidariedade e coesão social, quais sejam a exclusão e a segmentação com todas as consequiências hoje presentes: o desemprego, a pobreza, a violência, a intolerância. (PCNEM, 2000, p. 11).

Ainda, para as OCEM (2006, p. 91), "a disciplina Línguas Estrangeiras na escola visa a ensinar um idioma estrangeiro e, ao mesmo tempo, cumprir outros compromissos com os educandos, como, por exemplo, contribuir para a formação de indivíduos como parte de suas preocupações educacionais". E, ainda, para as mesmas OCEM, "[q]uando falamos sobre o aspecto educacional do ensino de Línguas Estrangeiras, referimo-nos, por exemplo, à compreensão do conceito de cidadania, enfatizando-o".

Nesse importante papel do ensino de inglês no IFSC, os docentes, nesse processo crítico, podem firmar a posição de mudança ou, por outro lado, perder o momento ensinando a língua pela língua apenas, isto é, detendo-se somente na forma e funções de determinadas expressões, como ocorre em muitas aulas de inglês, em que a reflexão crítica da contemporaneidade é deixada de lado:

[...] os professores de inglês podem cooperar em sua própria marginalização imaginando-se como meros "professores de língua" sem conexão alguma com questões sociais e políticas, ou então podem aceitar o paradoxo do letramento como forma de comunicação interétnica que muitas vezes envolve conflitos de valores e identidades, e aceitar seu papel como pessoas que socializam os aprendizes numa visão de mundo que, dado seu poder [...] deve ser analisada criticamente. (OCEM, 2006, p.109).

Em conjuminância com o as Orientações Curriculares para o Ensino Médio, cabe citar Celani (2008, p. 21), a qual assevera que a linguagem na escola, incluindo a língua inglesa, é “[f]undamental, já que é lá [na escola] que se está preparando os indivíduos para sua atuação como cidadãos com plena capacidade de atualizar seu potencial intelectual e afetivo na força de trabalho e na vida social como indivíduos esclarecidos e eficientes".

Os docentes do IFSC precisariam perceber as aulas de inglês como um espaço onde circulam valores diversos, os quais podem ser trabalhados, buscando-se a percepção de que os aprendizes tenham em mente que eles são os construtores da sua 
própria identidade, na maioria dos casos, em meio a forças que tentam condicionar os indivíduos a interesses de dominação. Havendo essa percepção por parte dos docentes, o ensino de língua inglesa assume o seu papel de formação do cidadão, o qual saberá realizar bem a sua atividade profissional técnica aprendida no IFSC, bem como saberá pensar e discutir o contexto em que está inserido e propor possibilidades diferentes, que levem em conta o lado humano, e não somente o interesse por destaque social e por lucro, tão difundido e buscado como meta de vida atualmente.

Tudo o que foi discutido até aqui aponta para a sugestão de um ensino inglês no IFSC baseado numa concepção libertária (FREIRE, 2011), que busque cooperar com o crescimento de cidadãos com plena capacidade, sujeitos que passam por um treinamento oferecido pela escola técnica, mas que também se vejam inseridos no mundo e que nele intervenham, que estabeleçam relações entre o que aprenderam e o seu universo sóciohistórico, pois os aprendizes "vão organizando uma forma cada vez mais justa de pensar, através da problematização de seu mundo, da análise crítica de sua prática, irão podendo atuar cada vez mais seguramente no mundo" (FREIRE, 2011, p.17). Esse, também, é o viés pelo qual a educação profissional é pautada no Documento Base, Educação Profissional Técnica de Nível Médio Integrada ao Ensino Médio, ao asseverar que

[m]as sob a perspectiva da integração entre trabalho, ciência e cultura, a profissionalização se opõe à simples a formação para o mercado de trabalho. Antes, ela incorpora valores éticos-políticos e conteúdos históricos e científicos que caracterizam a práxis humana. Portanto, formar profissionalmente não é preparar exclusivamente para o exercício do trabalho, mas é proporcionar a compreensão das dinâmicas sócio-produtiva das sociedades modernas, com as suas conquistas e os seus revezes, e também habilitar as pessoas para o exercício autônomo e crítico de profissões, sem nunca se esgotar a elas. (BRASIL, 2007, p. 45).

Ainda, é importante se observar que o ensino da língua inglesa (ou de qualquer outra língua) nas escolas precisaria ser visto como direito dos alunos e dever das escolas. O resultado seria de cooperação ao desenvolvimento de letramento para se viver em um mundo de fronteiras fluidas, tecnologias desterritorializadas - uma política linguística de crescimento do cidadão para ações pertinentes a sua própria vida, à vida social e à vida do trabalho. Portanto, percebendo-se que é direito do aprendiz se equipar de línguas estrangeiras, por que não ensiná-las e aprendê-las de forma que delas os aprendizes se valham para pensar, refletir e discutir as relações humanas? 
É nessa perspectiva da linguística do século XXI, de uma linguística crítica, que o ensino de línguas precisa ser desenvolvido; ensino que valorize as línguas como meio de relações transnacionais, transculturais; que veja o ensino de línguas como valor à diversidade linguística; como um bem, um direito das sociedades modernas nas suas relações; como um bem, um direito das comunidades minoritárias, quer sejam das áreas urbanas ou das rurais.

Esse ensino, como já foi dito, não caberia ser desenvolvido a partir de métodos e abordagens tradicionais, mas sugere-se que seja por meio de temas sociais que promovam o crescimento do cidadão crítico, como questões raciais, de tolerância a divergências de pensamentos e opiniões, de direitos humanos, de sexismo e outras questões; isso por meio de textos, vídeos, canções pertinentes, debates, apresentações, exposições, dramatizações, produções textuais e orais (tarefas). As questões de estrutura da língua e de gramática, nesse caso, podem ser resolvidas a partir das demandas dos estudantes ou quando forem fundamentais para o entendimento adequado do assunto abordado; não serão o ponto de partida nem o ponto de chegada.

\section{CONSIDERAÇÕES FINAIS}

No contexto atual, não é suficiente ensinar e aprender uma língua apenas para se comunicar, desfrutar de vantagens que ela possa trazer em termos empregatícios, financeiros. É importante que, além disso, a sua aprendizagem traga também entendimento do mundo em que o aprendiz está inserido, um mundo com os seus dilemas, diferenças e indiferenças, discriminações, ideologias, opressões, interesses corporativos, um mundo em que a globalização está mais a serviço de interesses particulares do que dos interesses das pessoas comuns.

Dessa forma, ensinar e aprender inglês pode preparar o aprendiz para o exercício da sua profissão com competência. As línguas (a língua inglesa) ganharam espaço importantíssimo no processo produtivo, pois é por meio delas que as inovações tecnológicas são difundidas e o resultado dos usos dessas tecnologias, os produtos (processo produtivo) e vendas são levados a cabo. Ainda, o domínio do inglês pode ajudar o estudante a se preparar, a crescer como cidadão reflexivo, que fará da língua aprendida instrumento de compreensão e de transformação de si mesmo e das questões contemporâneas não-humanizantes, o ajudará a reforçar e cultivar as ações que promovem o bem comum. 
Portanto, os campi do IFSC, onde o inglês é ensinado precisariam tratar essa língua como instrumento de competência crítica, de problematização ante os contextos estruturados nas desigualdades e exclusões. A língua inglesa de caráter geral e de caráter técnico pode ser ensinada sem deixar de lado as questões do dia a dia que demandam indagações e respostas advindas de mentes inquietas que visualizem um mundo mais justo, onde as minorias, as etnias, as mulheres, os menos favorecidos e discriminados sejam reconhecidos e tenham os mesmos direitos acessados por segmentos privilegiados.

\section{REFERENNCIAS}

APPADURAI, A. Disjuncture and difference in the global cultural economy. Theory, Culture \& Society. London: SAGE Publications Ltd, 1990. v. 7, p. 295-310. Disponível em: < http://journals.sagepub.com/doi/pdf/10.1177/026327690007002017>. Acesso em: 10 jan. 2017.

BRASIL. Ministério da Educação. Diretrizes Curriculares Nacionais Para Educação Profissional Técnica De Nível Médio. In __ . Diretrizes Curriculares Nacionais da Educação Básica. Brasília: MEC, SEB, DICEI, 2013. p. 209.

BRASIL. Ministério da Educação. Educação Profissional Técnica de Nível Médio Integrada ao Ensino Médio. Documento Base. Brasília: MEC, SETEC, 2007. p. 45. Disponível em:<http://portal.mec.gov.br/setec/arquivos/pdf/documento_base.pdf $>$. Acesso em: 10 jan. 2017.

BRASIL. Ministério da Educação. Secretaria de Educação Fundamental Proposta Curricular para a educação de jovens e adultos : segundo segmento do ensino fundamental: 5a a 8a série : introdução / Secretaria de Educação Fundamental, 256 p, 2002.: il. : $\quad$ v. $<$ http://portal.mec.gov.br/secad/arquivos/pdf/eja/propostacurricular/segundosegmento/v ol2_linguaestrangeira.pdf >. Acesso em: nov. 2016.

BRASIL. Senado Federal. Lei de Diretrizes e Bases da Educação Nacional: $n^{o}$ 9394/96. Brasília, 1996.

CAVALCANTI, M. C. A propósito de Linguística Aplicada. Trabalhos em Linguística Aplicada. São Paulo: UNICAMP, 1986. v. 7, p. 5-12.

CAVALCANTI, M. C.; MOITA LOPES, L. P. Implementação de pesquisa na sala de aula de línguas no contexto brasileiro. Trabalho em Linguística Aplicada. São Paulo: UNICAMP. 1991. v. 17, p. 133-144.

CELANI, M. A. A Relevância da Linguística Aplicada na Formação de uma Política Educacional Brasileira. In: FORTKAMP, Mailce Borges mota; TOMICH, Lêda Maria (Orgs). Aspectos da Lingüística Aplicada: Estudos em homenagem ao Professor Hilário Inácio Bohn. 2 ed. Florianópolis: Insular, 2008. p. 17-32.

COLLINICOS, A. Globalization, Imperialism and the Capitalist World System. In: HELD, David; MCGREW, Anthony (Ed.). Globalization Theory: Approaches and Controversies. Cambridge, UK: Polity Press, 2007. p. 62-78.

COUPLAND, N. Introduction: Sociolinguistics in the Global Era In: COUPLAND, Nikolas (Ed.) The handbook of language and globalization. United West Sussex, Kingdom: John Wiley \& Sons, Ltd., 2010. p. 01-29. 
FAIRCLOUGH, N. Language and Globalization. New York: Routledge, 2006.

FREIRE, P. Ação Cultural para a Liberdade. 14 ed. Rio de Janeiro: Paz e Terra, 2011.

FREITAS, M. T. de U. Ensino de Linguas como Transgressão: corpo, discursos de identidades e mudança social. São Paulo, Jundaí: PacoP Editorial, 2013.

GARCIA, O. Bilingual education in 21st century: a global perspective. United Kingdom: John Witly \& Sons Ltd, 2009.

GROSJEAN, F. Bilingual: life and reality. Cambridge, Massachusetts: Harvard Universtity Press, 2010.

HOLBOROW, M. Review of The Cultural International Language. In: RAJAGOPALAN, K. 2005. Postcolonial World and Postmodern identity: some implications for language teaching. Delta, 21: especial, 11-20, 1996.

KACHRU, B. B; NELSON, C. L. World Englishes. In: BURNS, Anne; COFFIN, Caroline (Ed.). Analysing English in a Global Context: a reader. London: Routledge, 2001. p. 9-25.

KUMARAVADIVELU, B. A lingüística aplicada na era da globalização. In: Por uma linguística aplicada Indisciplinar. São Paulo: Parábola, 2006. p. 131-147.

MAHER, T. Do casulo ao movimento: A suspensão das certezas na educação bilíngue e intercultural. In: CAVALCANTI, M. ; BORTONI-RICARDO, S.M. Transculturalidade, linguagem e educação. Campinas: Mercado de Letras, 2007.

MEGALE, A. H. Bilíngue, eu? Representações de sujeitos bilíngues falantes de português e inglês. Revista X, v. 2. [S.l.]: UFPR, 2012. Disponível em: < http://revistas.ufpr.br/revistax/article/view/28181/20384>. Acesso em: 15 nov. 2015.

MOITA LOPES, L. P. Linguística aplicada na modernidade recente: Festchift para Antonieta Celani. São Paulo: Parábola, 2013.

OCEM - ORIENTAÇÕES CURRICULARES PARA O ENSINO MÉDIO. Brasília: Ministério da Educação, Secretaria de Educação Básica. 2006, volume 1, 239 p.

PCNEM - PARÂMETROS CURRICULARES NACIONAIS (ENSINO MÉDIO). Brasília: Ministério da Educação. Secretaria de Educação Média e Tecnológica, MEC, 2000.

PDI-PLANO DE DESENVOLVIMENTO INSTITUCIONAL DO IFSC, 2015-2019. IFSC: O futuro em construção. Florianópolis: IFSC, 2014. Disponível em :

< http://www.ifsc.edu.br/images/copadin/PDI_IFSC_versao_final_menor.pdf >. Acesso em: 23 nov. 2016.

PDI-PLANO DE DESENVOLVIMENTO INSTITUCIONAL DO IFSC, 2009-2013. IFSC: O futuro em construção. Florianópolis: IFSC, 2009. Disponível em:

$<\quad$ http://ararangua.ifsc.edu.br/site_old/docs/planejamento/PDI\%20-

$\% 20$ Plano\%20de\%20Desenvolvimento\%20Instituicional.PDF>. Acesso em: 23 nov. 2016.

PENNYCOOK, A. Linguística aplicada dos anos 90: Em defesa de uma abordagem crítica. IN: SIGNORINI, Inês; CAVALCANTI, Marilda, C. (Orgs.) Línguística Aplicada e Transdisciplinaridade. Campinas: Mercado de Letras, 2007.

. Uma lingüística aplicada transgressiva. IN: MOITA LOPES, L. P. (Org.).

Por uma linguistic aplicada indisciplinar. São Paulo: Parábola, 2006, p. 67-84.

Critical Applied Linguistics: a critical introduction. Mahwah, New Jersey: Associates, Inc., Publishers, 2001.

RAJAGOPALAN, K. Postcolonial World and Postmodern identity: some implications for language teaching. Delta, 21: especial, 11-20, 2005.

SHIN, J. S. Bilingualism in schools and society: language, identity and policy. New York: Routledge, 2013. 


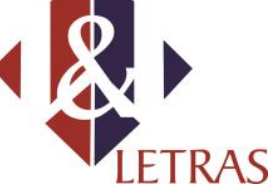

e-ISSN: 1981-4755

DOI: $10.5935 / 1981-4755.20170010$

STEGER, M. B. From Market Globalism to Imperial Globalism: Ideology and American Power after 9/11. Globalization. V. 2, N. 1, p. 31-46, 2005. <http://dx.doi.org/10.1080/14747730500085049 >. Acesso em: 15 nov. 2016.

UDOFOT, I. The English Language and Politics in Nigeria. Journal of the Nigeria English Studies Association. Nigeria, Mushin, Lagos: Olivetree Publishing Ventures, v. 13, set. 2010.

Data de recebimento: $12 / 01 / 2017$

Data de aprovação: 23/05/2017 